\title{
What's Wrong with the Railways?
}

\author{
Graeme McLay \\ Transportation Research Group, University of Southampton \\ United Kingdom
}

\begin{abstract}
Transportation research often focuses on the problem of persuading travelers to switch from private to public transport. Lists are drawn up that note the differences between private and public transport and emphasize the environmental benefits and efficiencies that can be gained from a modal shift. New technologies or even new modes are studied to combat the ever-growing popularity of private transport. Yet, car ownership and travel continue to increase. Instead of asking what would persuade car drivers to travel by public transport, this article focuses on the question: What's wrong with the railways that make people prefer to drive?

This research follows an earlier paper in the Journal of Public Transportation (Lyons and McLay 2000) and presents some observations on the state of passenger railway in the United Kingdom. Complaints about passenger rail continue to rise (see Office of Passenger Rail Franchising [OPRAF] 1999 and Office of the Rail Regulator [ORR] 1999). While there may be a number of reasons for this rise, including increased press coverage and improved complaint procedures, it is clear that a lack of investment in rail infrastructure led to increased delays and reliability (Department of the Environment Transport and the Regions [DETR] 1998). It is not clear from these statistics as to what people who continued to use the railway actually thought about the service. The Association of Train Operating Companies (ATOC) granted access to its collection of complaints to make further inquiries, which showed that those who do use the railways are generally satisfied with the service.
\end{abstract}




\section{Complaints}

Written complaints filed with ATOC between the beginning of January 1998 and the end of January 1999 were examined and sorted by type of complaint, according to a scenario structure created beforehand. (The process of complaints arriving at ATOC is described in Lyons and McLay 2000). A database was created in Microsoft Access to record information contained in the letters. Any information that gave details of recovery solutions, presentation of information, costs and time spent on any problem was entered into the database. Many letters gave journey details such as date, time, origin, and destination, allowing a comparison to be made between weekday, holiday, and weekend journeys. Journey time highlights differences between the actual times the passenger made on the journey and the times predicted by advance planning agencies such as the National Rail Enquiries Service (NRES).

Also detailed were journey planning information, including verification through repeat searching, showing the efforts people make to acquire information, what source they use, and how much they trust it.

Additional information discussed solutions that were presented to passengers in recovery situations (i.e., trying to continue a journey that did not progress as planned). Passengers' opinions on the suitability of this information were recorded.

These complaint letters are an extremely biased sample, mostly covering situations that are the fault of the rail service and not the fault of the traveler. For example, they mention arriving late at the departure station and missing the train. The letters are a record of people who are unhappy enough with their rail experience that they have complained. They are also all written complaints and biased by being only the complaints of people who would write to complain. There would always be bias retrospectively treating data as a set of survey responses. An overview of the information items identified from the complaint letters and the "responses" collected is given in Table 1.

The frequency chart shows that the days most complained about are not commuting days, but weekends (and holidays) when passengers are not on their usual journeys. Table 2 shows that the current system of telephoning for information and getting a quote for the fare is not working properly. Between the NRES operator, prospective passenger, and ticket office, there is confusion over journey prices and schedules. It may be that the passenger is not clear with the phone operator about the desired trip ( 14 complaints concerned the wrong schedule) or that the 


\section{Table 1. Overview of the Survey Information}

\section{Total complaints examined: 105:}

A bout actual journeys: 80

A bout information only: 25

\section{Incorrect details about:}

Departure time: 16

Price: 22

0 ther: 14

N ot told about a service: 8

Told about a nonexistent service: 21

Remaining complaints concerned late changes and delays.

\section{Of the actual journeys made, the causes of complaints were:}

Engineering works: 7

$\mathrm{N}$ atural phenomenon: 3

Given wrong schedule: 14

Given wrong price: 15

D issatisfied with information: 20

Train either broke down or was delayed: 11

Cause not given: 8

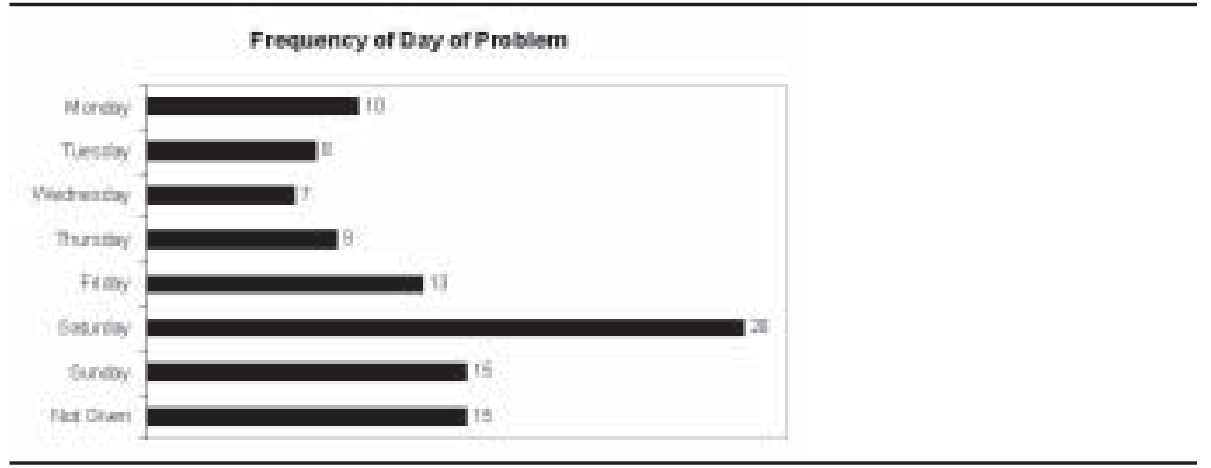

Of the Monday to Fridays, 7 were during holidays (Bank, Easter, C hristmas)

\section{En route information sources:}

Staff: 34

Monitor: 1

Timetable: 2

P.A.: 3

N RES: 20

0 ther phone: 8

N otice board: 3

Arrival/departure notice: 5

0 ther: 4 (Internet uncited)

Additional expenses: 40; Time costs: 16

Passengers who thought recovery information was not enough: 17
Passengers given another option:

Train: 44; Suitable: 16

Mode: 20; Suitable: 6 
operator used an out-of-date timetable (21 complaints concerned a nonexistent service). In any event, the passenger is not getting the desired information. If the passenger cannot get this information before making the journey, this has implications for customer satisfaction.

\section{Table 2. Frequency of Occurrence}

\begin{tabular}{|lc|}
\hline Scenario & Percent \\
\hline Price is different from quote & 26 \\
Train is different from that expected & 20 \\
Train cancelled & 14 \\
Train stops at intermediate station & 8 \\
Train runs behind schedule & 6 \\
Get to station, train gone & 4 \\
Get to train, does not depart & 4 \\
Train departs late & 3 \\
Get to station, can not find train & 2 \\
Train arrives late & 2 \\
Train does not stop at expected station & 2 \\
Train stops outside station & 2 \\
Get to station, imminent departure & 1 \\
\hline
\end{tabular}

While these passenger complaints represent an extremely biased sample, they show that certain situations generate dissatisfaction. A train in some way different from that expected, because the schedule or the price is different, causes the most complaints. While these situations would benefit by improving communication between the passenger and the operator, the remainder of this article describes the satisfaction of regular train passengers with the service they receive. Complaints were bundled according to the information needed to resolve them and particular attention was given to those that might affect actual rail journeys as opposed to those that would benefit from more reliable information at the outset. For this reason, and because the research was already investigating recovery situations, passengers were asked their opinions of the service they received when something went wrong with their journey to find out if there is something wrong with the railways that is encouraging people to drive. 


\section{Survey}

Scenarios were developed from the complaints that matched the broad groupings in Table 2. Passengers were asked what they would do if faced with these situations for their journey (for more on this process, see McLay and Lyons 2000). Although there are many problems with survey data (Oppenheim 1996), matching scenarios to the journeys actually taken by passengers, and having them fill out the journey survey where possible, would provide more reliable information. Survey biases and the measures used to control them are noted in Table 3.

\section{Table 3. Survey Biases}

\begin{tabular}{|l|l|l|}
\hline Bias & Nature of Bias & Controlling Measure \\
\hline Participants & Age/gender/experience & $\begin{array}{l}\text { O btain demographic details of } \\
\text { South W est Trains passenger } \\
\text { population }\end{array}$ \\
\hline Experimenter & $\begin{array}{l}\text { Participant selection, effects } \\
\text { on participants }\end{array}$ & $\begin{array}{l}\text { Approach all passengers with } \\
\text { prepared speech, depart during } \\
\text { participation }\end{array}$ \\
\hline Q uestionnaire & $\begin{array}{l}\text { Stated preference/memory/ } \\
\text { desire }\end{array}$ & \begin{tabular}{l} 
Context \\
\hline Train
\end{tabular} \\
\hline Rolling stock, express/stopping & $\begin{array}{l}\text { Sample different stock and } \\
\text { journey types }\end{array}$ \\
\hline of the day & $\begin{array}{l}\text { Careful selection as outlined } \\
\text { above }\end{array}$ \\
\hline
\end{tabular}

In fact, post survey analysis showed that there were no significant differences in responses between people who returned the surveys on the train and those who sent them back later. The survey route chosen in consultation with South West Trains was from Bournemouth to Woking (as shown in Figure 1). The route was long enough to allow some modal competition, variations in the event of a breakdown, varied origins and destinations (either internal or external to the route) allowing connections, onward journeys, and have commuter and leisure users. 


\section{Figure 1. Survey Route}

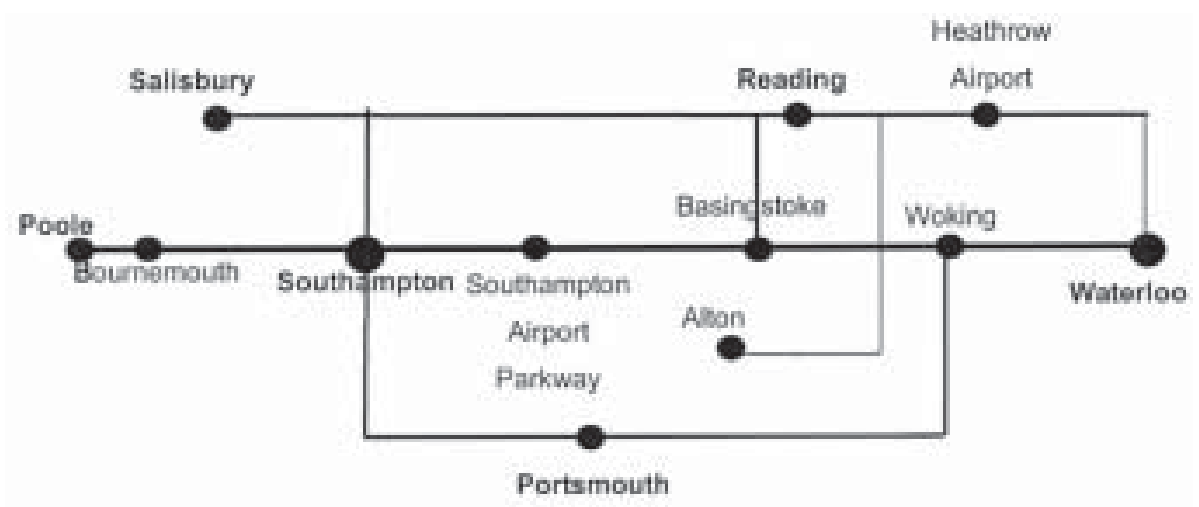

The route is popular with commuters and people traveling from the west into London. There are direct and stopping services and competing coach services. Passengers can disembark at Southampton or at Woking for the coach to Heathrow. Most travelers remain on board for London Waterloo. There were also a variety of ways to get to the station, including the underground in London and the ferry in Southampton.

After piloting the survey in March 2000, three dates were chosen around Easter for disseminating it. The timing of the survey around Easter would allow more people who were unfamiliar with their journey, and who, therefore, might be in more need of information, to be sampled. Wednesday, April 19, was chosen as a regular mid-week day. April 20 was included because there happened to be a strike by South West Train drivers, causing even regular travelers to seek more information than usual, and which allowed a comparison to be made with a follow-up survey one week later.

\section{Analysis}

Of the 1,200 questionnaires handed out, 550 were useable; 298 were collected on board the train and 252 were mailed back. (This $46 \%$ response rate compares very favorably with an industry standard of 33\%.) Testing on differences of proportions shows a match within 95 percent confidence levels across all demographic categories between the survey results and South West Trains's demographic profile, although there is a higher number of the $35-54$ age group in the survey $(53 \% \mathrm{v}$. $37 \%)$. Across almost all questions there was little statistically significant difference in responses between those mailed back and those collected by hand. There were 
more 25- to 34-year-olds who mailed back their responses $(z=2.583)$ and more 35 - to 54 -year-olds who returned them by hand $(z=2.245)$. This may be a consequence of young professionals working on the train and older people using the questionnaire to pass some time on the journey. These statistics mean that the results of the questionnaire can reasonably be assumed to apply to the passenger rail-using population. They also mean that mail-back questionnaires can be used to obtain data from the rail-using population, rather than collecting surveys by hand. Unless otherwise stated, there were no significant differences in responses by gender, age, or number of passengers traveling.

Passengers were asked how often they traveled by rail to test any effect of experience of incidents on actions. Of those who traveled by rail once a week or less, 52 percent would take a car if the train were not available, while 34 percent would cancel the trip. Of those who travel most days in the week, 38 percent would use a car, but 53 percent would cancel. Perhaps people who make irregular journeys place a higher value on them, while it may be that people who commute feel more able to use the rail company as an excuse to skip work.

Nearly 60 percent of the respondents drove or were driven to the station; 48 percent would have driven if the train were not available for that day's journey. These numbers indicate that half the sample could have driven if they wanted, but they prefer to take the train. Removing the effect of the London Underground from the sample (those traveling toward London cannot use the tube to get to the station), a chi-square test showed no significant difference at the 0.05 level between days 1 and 3 for methods of getting to the station. However, on day 2 (strike) more people drove to the station. Most people seem to have reasonably fixed methods of getting to the train station despite changing conditions (workday, strike, or holiday) as illustrated by the float times people allowed to catch a train. Analysis of variance showed no significant difference across days for leaving for the station earlier than necessary, arriving at the station early, or catching an earlier train. 
Clearly, people who use the rail service, use it repeatedly. They may not feel like they have any real alternative, but they do continue to travel by rail. Table 4 shows that more than half the sample traveled at least once a week by train, with a further 17 percent traveling once a month. This experience of the rail service will effect information requirements.

\section{Table 4. How Often Passengers Travel by Rail}

\begin{tabular}{|lc|}
\hline Frequency & Percent \\
\hline Most days in the week & 43 \\
A bout once a week & 17 \\
Around once a month & 17 \\
A few times a year & 20 \\
Less than once a year & 1 \\
Unspecified & 1 \\
\hline
\end{tabular}

Part of people's rail experience is how they have found the service to be in the past. Of the 550 respondents, 146 had previously made a written complaint about the rail service, covering 180 "offenses." In 1998-99, there were 875,878,252 journeys nationally and 737,331 written complaints (ORR 1999). Based on this rate, 146 complaints represent 173,448 journeys, which explains why a researcher could not cover all the situations that resulted in complaints.

Table 5 demonstrates that it is the actual provision of rail services that generates the most complaints. It also shows that a substantial number of complaints concern information (or its lack) and occasions when there have been disruptions to the rail service and passengers felt they could have been better informed.

When there is a problem with a rail journey, a person's prior experience of rail incidents can affect how they get information to recover the journey. Of those who travel by rail only a few times a year, 6 percent wanted to ask rail staff how to continue a journey that had been delayed. Less than 1 percent of more frequent travelers wanted this information. Commuter travelers seemed to know what their options were when they were on their daily trip; 49 percent of those who travel weekly wanted to know what their options were to recover a journey, but this fell to 19 percent for those traveling a few times a year. This group was more interested in getting clear information about the delay and in being told how to proceed (rather than choosing from options) than any other group. 


\section{Table 5. Passenger Complaints}

\begin{tabular}{|lc|}
\hline Complaint Categories & Percent \\
\hline Punctuality/D elay & 27 \\
Late train & 22 \\
Information & 13 \\
O vercrowding & 8 \\
Cost & 7 \\
Train cancelled & 5 \\
Train broke & 4 \\
Miscellaneous & 14 \\
\hline
\end{tabular}

People can only seek information when they know what is available. To understand this, passengers were asked how they got information to make the current journey. More than one information source was used, perhaps because people could not find the information they wanted from the initial source or because they wanted to double-check. The 550 survey respondents totaled 632 sources as shown in Table 6. The largest group relied on their own prior knowledge. Of the 27 percent who used a paper timetable, half did not carry one on the current journey, so 16 percent of travelers were using a paper timetable purely for pretrip information. From the survey, 69 percent could not give a reasonable approximation of the NRES number. A number of people indicated that they did not know about the NRES.

Table 6. How Passengers Received Information

\begin{tabular}{|lc|}
\hline Information Source for This Journey & Percent \\
\hline Prior knowledge & 36 \\
Paper timetable & 27 \\
Telephone (N RES) & 12 \\
Didn't use any & 11 \\
Internet & 6 \\
Information kiosk & 3 \\
Telephone (other) & 1 \\
O ther & 4 \\
\hline
\end{tabular}


Business travelers used the Internet more than any other group. Of 25 passengers who had an itinerary/Internet printout, 18 were on business. Fifty-three percent of all business travelers had a laptop, representing 68 percent of all laptops on the train.

Figures vary, but upwards of 25 percent of people in the United Kingdom have accessed the Internet (for Internet usage, see: British Broadcasting Corporation 2000; Richardson 2000; Allegra 2000). This number can only rise. The number who will use the Internet for pretrip travel information remains open to question. Of the 37 Internet users in the survey, all but 6 said they would use a computerized traveler information system. It is unclear why 6 people who already use the Internet would not use a computerized system, though one reason may be that their current experience has shown that while the Internet may provide reliable pretrip information, it is not capable of providing incident information. Real-time data is now available and could solve this problem. Another problem may be cost. If Internet users get free access at work, they may be less inclined to pay for Internet access themselves. Most households now have a telephone, half the U.K. population has a mobile telephone, yet only 13 percent of the sample used it to get information. Just because one has the equipment does not mean they will seek the information.

More than 70 percent of the respondents had either a mobile phone or a portable computer (14\% carried a computer). Of these, 66 percent did not know the NRES number. Nearly half the sample carried a timetable booklet with them, although 31 percent had not used it to get information for the current journey. Presumably they know where they are going and carry the timetable out of habit or for emergencies.

Even under optimum conditions, useful information systems must present items wanted by passengers. Asked to pick the most important item from a list, passenger order of main preference for the current journey was first available train (30\%), followed by shortest journey time (29\%), lowest price (14\%), and getting a seat (12\%). For general rail travel, passengers prioritized their requirements as shortest journey time (41\%), fewest connections (21\%), lowest price (19\%), and first available train (13\%). These results show how important travelers view quickness of journey. However, enough respondents also requested getting a seat to have made this as desirable as catching the first available train. During an incident, 24 percent wanted updated arrival or departure information, 26 percent wanted to know the length of the delay, 13 percent wanted to know the cause, 3 percent wanted to 
know how it was going to be fixed, while 21 percent did not want any information at all. They were content to wait and be informed.

Passengers were asked attitudinal questions about journey recovery situations. These questions were based on South West Trains internal Satisfaction Information System (Figure 2), which found staff was not seen as helpful, although the response of staff was thought to be clear.

Figure 2. SWT Satisfaction Information System

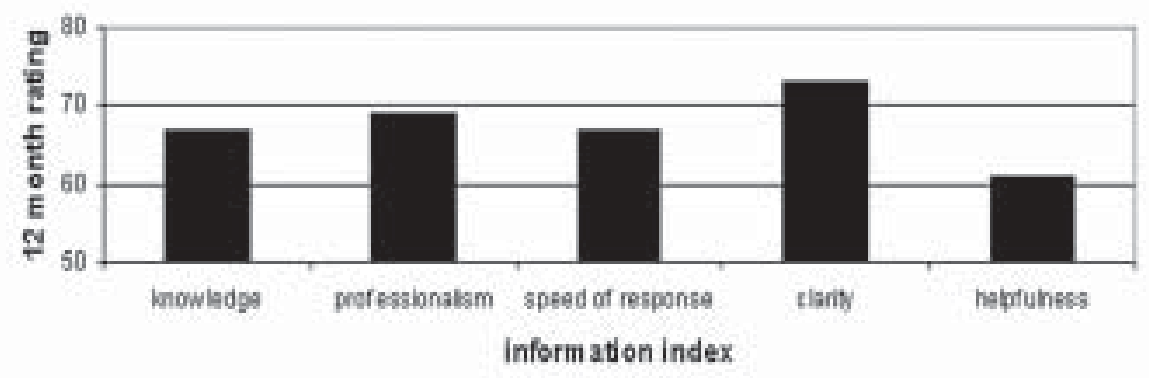


Figure 3 shows that survey respondents found staff as more helpful than clear. Travelers also felt that they had enough information to proceed with their journey, but they were less impressed with information available to overcome problems during a journey.

\section{Figure 3. Attitude to Problems}

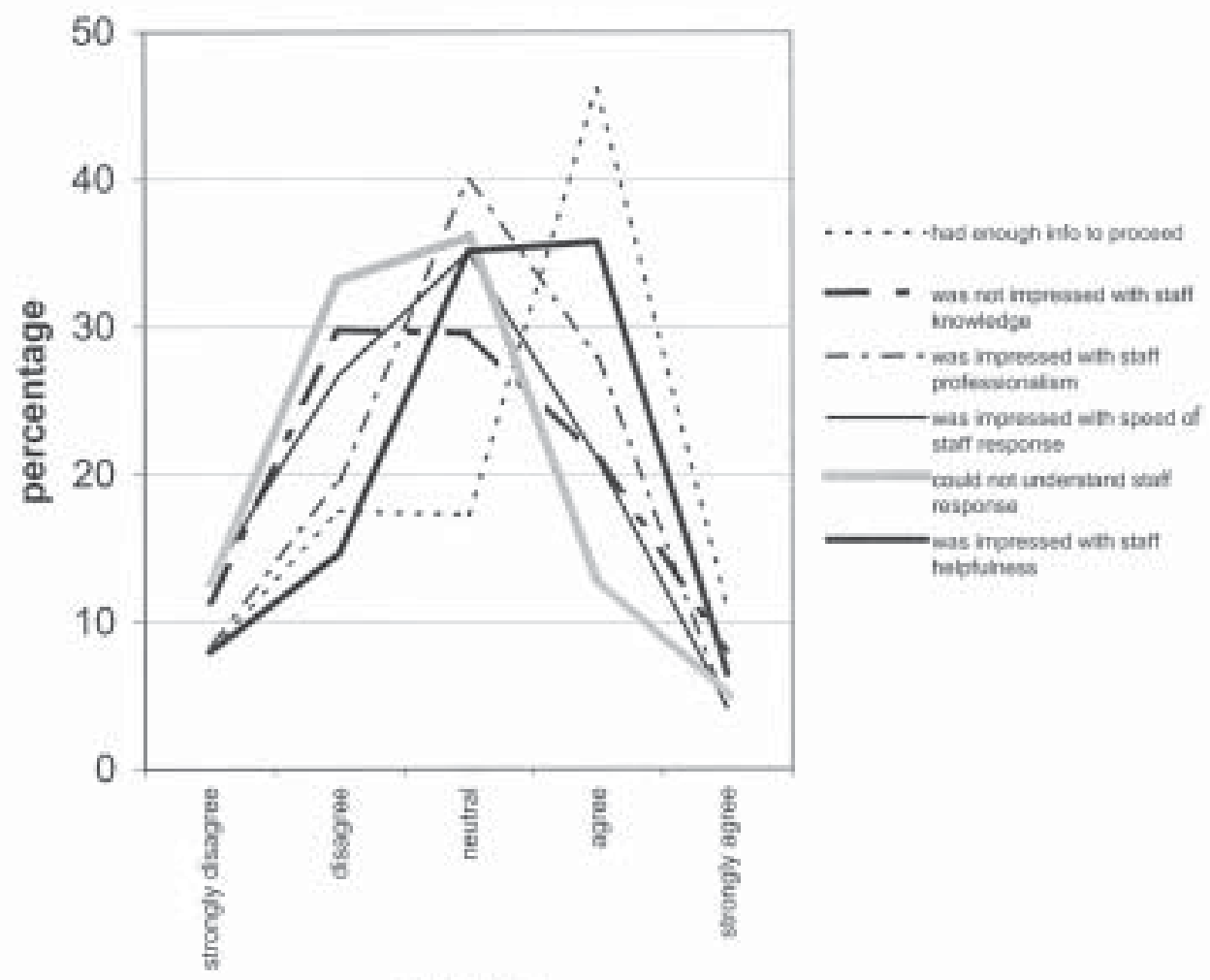

attitude

When queried as to what they want in terms of improvements to the rail service, Figure 4 shows that the passengers' highest requests were for more trains or seats, or using existing trains more effectively (e.g., by allowing passengers without seats to use unoccupied spaces in first class). Better quality information and advice, especially improved public announcement clarity, was the next mentioned item. 


\section{Figure 4. Passenger Wants}

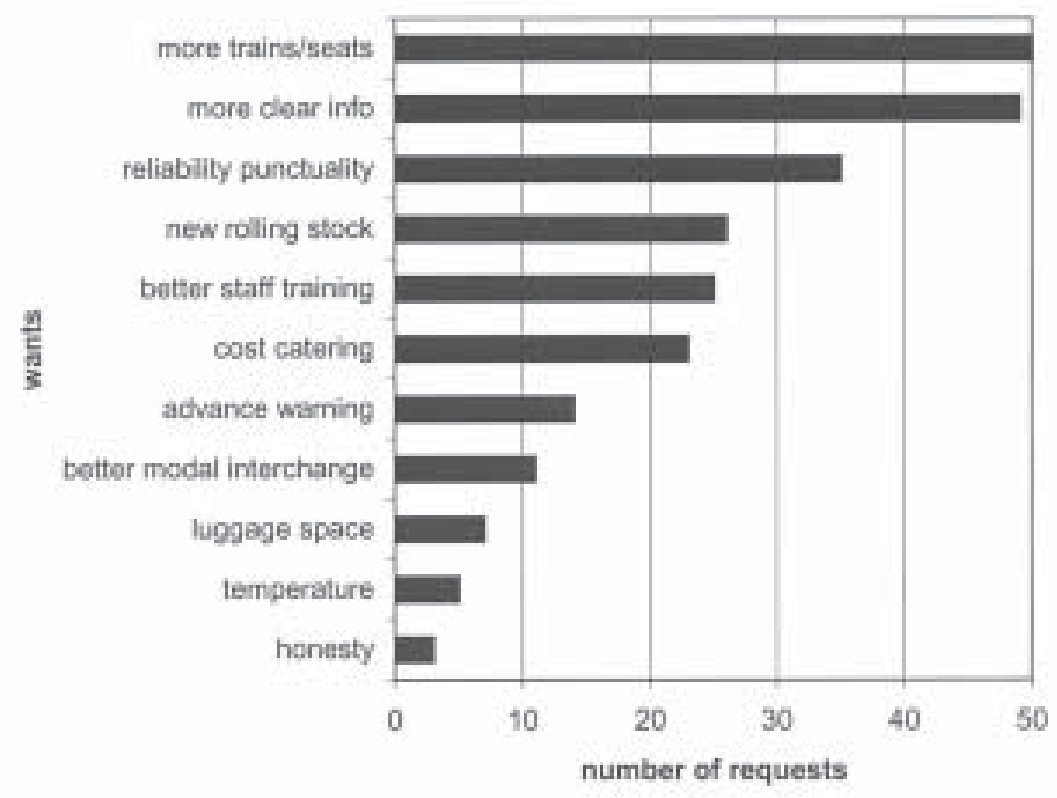

There were 12 mentions of real-time information. Some suggested it was not currently feasible, but most said it was desirable. These mentions of real-time information are valuable because they were spontaneous. People who do not know about the possibilities from information technology cannot suggest improvements, placing a higher value on unprompted recommendations.

Prompt arrival time was important for 62 percent of the respondents. Adverse consequences include missing events and connections, making a bad impression, having to work late, incurring a financial cost, stress, and having to wait. Despite the importance attached to these 183 references to arriving on time, people were not prepared to pay to obtain information that could overcome a problem with their journey. Figure 5 shows that there can be quite a delay before passengers feel the need to replan a journey. 


\section{Figure 5. Delay Before Replanning Journey}

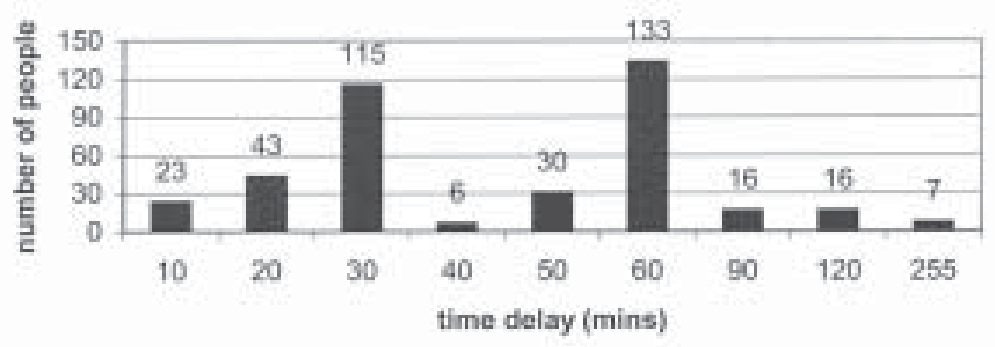

\section{Conclusions}

The above analysis indicates that there is considerable good will toward the passenger rail industry. Passengers are habitual (nearly two thirds travel every week, half could drive). They prefer the human touch when it comes to information ( $79 \%$ would ask staff what to do if a train was cancelled), but they will use technology as well. The Train Operating Company (TOC) should ensure that its staff has the most accurate information possible.

When there is a problem, passengers will wait for delayed trains. They want to be kept informed, but most will remain with the rail network rather than seek an alternative mode. Passengers want to know what is going on and what the TOC is doing about it. They want to know the quickest way of getting to their destination, but in the event of an incident they are prepared to wait for the TOC to find a solution for them. TOCs should provide passengers with information that will enable them to continue with their journey by rail. This loyalty/apathy is particularly manifested in the way passengers think about punctuality. TOCs are obliged by the regulator to consider a train that arrives five minutes after the scheduled time as late. This is in contrast to the way car drivers think of punctuality or the way passengers think of lateness, which only occurs when they miss a connection or the start of a meeting. Compare this situation with a sports event in which the start may be delayed to allow spectators to get to their seats. This is considered desirable. Rail travel has not been allowed this sort of flexibility, even though passengers may consider it desirable. 
During the fuel crisis of September 2000, while the rail regulator was praising the efforts of rail staff to get to work, the media reported trains failing to cope with the influx of people who were unfamiliar with the rail system (Strategic Rail Authority 2000). TOCs need to get better press. Advanced information promotes a feeling that the rail company is looking to make improvements and will also deliver network benefits in improved operation of the network, both for the TOC and the passengers. The introduction of pocket PCs will enable front-line staff to provide accurate timetable information. Some TOCs have begun loading this information onto the Internet. Furthermore, this information must be integrated. Passengers expressed an interest in a better modal interchange (see JourneyWeb 1999; PTI 2000).

Rail companies need to advertise information sources; 70 percent of passengers could not give an approximation of the NRES number. If the TOCs display the NRES number in every carriage, this would enable those phone carriers who do not recall the NRES number to use the service. It would also inform passengers who do not know about NRES that the service is available. More than a third of those surveyed by the Association of Transport Co-ordinating Officers, when prompted about the availability of information agreed that "if it were easier to get information about public transport services, I would use public transport more" (Association of Transport Co-ordinating Officers 2000). In the same survey, just 21 percent of respondents who would consider making a long-distance trip by train mentioned NRES as a source of information. None of those whose train was cancelled at the outset used NRES for recovery information despite nearly two-thirds of those who used NRES describing it as completely accurate (Harris Research Centre 1998).

It may seem obvious that passengers want modern carriages. Tables 1 and 6 show that passengers complain about the condition of the railway service (actual journeys, overcrowding, delays) more than they complain about information. Rail companies know this and are already expending most of their efforts in this area (Stagecoach has announced a $£ 1.5$ billion order for new trains that should generate an extra 70,000 peak-time seats per day. An additional $£ 137$ million will be spent refurbishing existing rolling stock.). However, TOCs may not appreciate the depth of feeling in this matter. Forty percent of the survey sample wanted to ensure they had a seat for their journey. Passengers want empty first-class carriages to be made available when there are no seats left in standard class. 
There is a popular perception that rail (in the United Kingdom at least) is old, dirty, and inefficient (see Automobile Association 1997; delayed.net 1999). This view appears to be held most strongly by people who do not regularly travel by rail or who tried rail during the fuel crisis when the services were overstretched. It appears that those who regularly travel by rail are largely satisfied with the service. The upgraded rolling stock should at last be some good news to persuade car drivers that there is nothing wrong with the railways.

\section{Acknowledgements}

Many thanks are owed to all rail staff who allowed access to the railway for collecting surveys, in particular Elizabeth de Jong and her staff at South West Trains. 


\section{References}

Allegra. 2000. Project icon-Internet "on-the-move" in the UK. http:// www.allegra.co.uk/projecticon.htm accessed October 24, 2000.

Association of Transport Co-ordinating Officers. 2000. Potential demand for national integrated transport information. http://www.atco.org.uk/pti/harris/ niptifinal.htm.

Automobile Association. 1997. Living with the car: 27-28.

British Broadcasting Corporation. 2000. Home Internet use "growing." http:// news.bbc.co.uk/low/english/uk/newsid_869000/869927.stm accessed October 24, 2000.

delayed.net. 1999. http://www.delayed.net/ accessed June 7, 1999.

Department of the Environment Transport and the Regions. 1998. A new deal for transport: better for everyone. Transport White Paper. London: The Stationery Office.

The Harris Research Centre. 1998. National rail enquiry service customer perceptions. Table 7.

JourneyWeb. 1999. http://journeyweb.civil.soton.ac.uk accessed November 7, 2000.

Le Squeren. 1991. Passenger information. Proceedings, DRIVE Conference: Advanced telematics in transport, 2, $1205 \mathrm{ff}$.

Lyons, G. D., and G. D. McLay. 2000. The role of information in the U.K. passenger rail industry. Journal of Public Transportation 3 (3): 19-41.

McLay, G. D., and G. D. Lyons. 2000. From laughing stock into rolling stock: Can rail passenger information help make a difference? Proceedings, Universities Transport Studies Group 32 ${ }^{\text {nd }}$ Annual Conference, II.

Office of Passenger Rail Franchising. 1999. Performance of the passenger rail network: 20 September 1998-12 December 1998. http://www.opraf.gov.uk/docs(/ bulletin/10/overview/performance_of_the_passenger_rai.htm accessed February 12, 1999.

Office of the Rail Regulator. 1999. Rail Complaints Bulletin. Report No. 3. http:// www.rail-reg.gov.uk accessed August 27, 1999. 
Journal of Public Transportation,Vol. 6, N o. 1, 2003

Oppenheim A. N. 1996. Questionnaire design and attitude measurement. London: Heinemann.

PTI 2000. 2000. Traveline http://www.traveline.org.uk accessed November 7, 2000. Richardson T. 2000. Brits flock to the Net. http://www.theregister.co.uk/content/ 1/12590.html accessed October 24, 2000.

Strategic Rail Authority. 2000. SSRA chairman welcomes rail passenger growth. http:/ /www.sra.gov.uk accessed September 15, 2000.

\section{About the Author}

Graeme McLay (G.McLay@soton.ac.uk) is a researcher in the Transportation Research Group at the University of Southampton. His doctoral thesis (2001) examined the way rail passengers use information to recover rail journeys. His previous academic work was in arts (philosophy and psychology) and information technology at the University of Glasgow. 